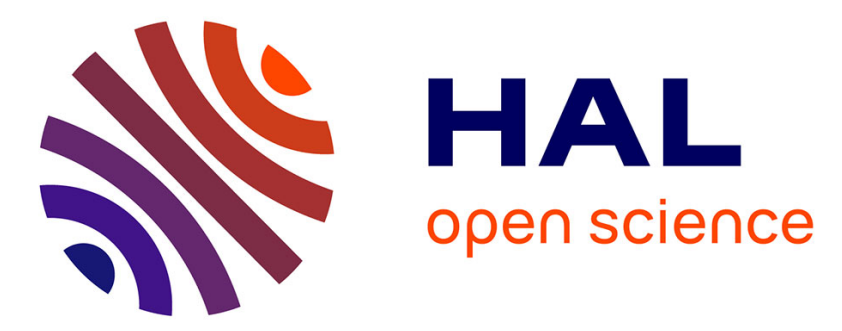

\title{
Experimental study of the combination of a positive input ventilation and active air vents on the air change rates of a house
}

Antoine Leconte, Clément Lafféter, Thomas Fritsch, Nicolas Giordano, Julien Escaich, Ophélie Ouvrier-Bonnaz

\section{To cite this version:}

Antoine Leconte, Clément Lafféter, Thomas Fritsch, Nicolas Giordano, Julien Escaich, et al.. Experimental study of the combination of a positive input ventilation and active air vents on the air change rates of a house. International journal of ventilation, 2020, pp.1-11. 10.1080/14733315.2020.1777017 . cea-02948515

\section{HAL Id: cea-02948515 https://hal-cea.archives-ouvertes.fr/cea-02948515}

Submitted on 24 Sep 2020

HAL is a multi-disciplinary open access archive for the deposit and dissemination of scientific research documents, whether they are published or not. The documents may come from teaching and research institutions in France or abroad, or from public or private research centers.
L'archive ouverte pluridisciplinaire HAL, est destinée au dépôt et à la diffusion de documents scientifiques de niveau recherche, publiés ou non, émanant des établissements d'enseignement et de recherche français ou étrangers, des laboratoires publics ou privés. 


\section{Experimental study of the combination of a positive input ventilation and active air vents on the air change rates of a house}

Antoine Leconte, Clément Lafféter, Thomas Fritsch, Nicolas Giordano, Julien Escaich \& Ophélie Ouvrier-Bonnaz

To cite this article: Antoine Leconte, Clément Lafféter, Thomas Fritsch, Nicolas Giordano, Julien Escaich \& Ophélie Ouvrier-Bonnaz (2020): Experimental study of the combination of a positive input ventilation and active air vents on the air change rates of a house, International Journal of Ventilation, DOI: 10.1080/14733315.2020.1777017

To link to this article: https://doi.org/10.1080/14733315.2020.1777017

Published online: 30 Jun 2020.

Submit your article to this journal $\pi$

山 Article views: 2

Q View related articles 두

View Crossmark data $₫$ 


\title{
Experimental study of the combination of a positive input ventilation and active air vents on the air change rates of a house
}

\author{
Antoine Leconte ${ }^{a}$, Clément Lafféter ${ }^{b}$, Thomas Fritsch ${ }^{c}$, Nicolas Giordano ${ }^{c}$, Julien \\ Escaich $^{\mathrm{b}}$ and Ophélie Ouvrier-Bonnaz ${ }^{\mathrm{a}}$ \\ a Université Grenoble Alpes, CEA, LITEN, DTS, INES, Grenoble, France; ${ }^{b}$ Ventilairsec, Couëron, France; \\ 'Bubendorff, Attenschwiller, France
}

\begin{abstract}
This study aims to experimentally evaluate the influence of the combination of a supply only ventilation, called here positive input ventilation, and innovative active air vents on the Indoor Air Quality of a house. The positive input ventilation draws fresh air from the outside, filters and pre-heats it before supplying it to living areas. Active air vents are small motorised dampers set up in the upper part of windows able to move according to local pollutants measurements or to the measurements of other active air vents in the house. This combination is expected to improve the Indoor Air Quality by increasing efficiently the air change rate of a room when it is too polluted. The goal of the tests presented in this paper is to evaluate quantitatively the air change rate in a real size environment. To do so, a positive input ventilation and active air vents are set up in an experimental house. The tests were carried out in 3 different rooms. For each room, the air change rate is evaluated for different configurations of the combination. $\mathrm{CO} 2$ is used as a trace gas to evaluate the air change rate. Results are promising and show that the studied combination allows a significant of the air change rate of each room. An appropriate Demand Control Ventilation strategy based on the sensors of each active air vents and the communication between all the devices would thus lead to an efficient while simple improvement in the use of a positive input ventilation system.
\end{abstract}

\section{ARTICLE HISTORY}

Received 20 February 2020

Accepted 20 May 2020

\section{KEYWORDS}

Positive input ventilation; active air vents; real scale experimentation; air change rate estimation

\section{Introduction}

Indoor air pollution is one of the biggest environmental risks to public health. Most policies, at European scale (European Commission, 2013) and national scales (e.g. (Direction générale de la Santé, 2013) in France), agree on the importance of improving the indoor air quality and the related benefits. On the other hand, new buildings are more and more airtight to reduce their energy consumption. Thus, ventilation systems have a large impact on energy, Indoor Air Quality (IAQ) and thermal comfort in dwellings (Liddament, 2000). That is why efficient ventilation systems are required to ensure healthy and comfortable internal environment while keeping an appropriate level of energy consumption (Chenari, Dias Carrilho, \& Gameiro Da Silva, 2016). Among efficient ventilation strategies, Demand Control Ventilation (DCV) aims to adjust the 
ventilation according to the needs. Numerous DCV systems have been studied for decades and have proved their potential for energy reduction, as reviewed by (Fisk \& De Almeida, 1998) and (Guyot, Sherman, \& Walker, 2018) for instance. DCV strategies for dwellings are based on IAQ sensors, mainly relative humidity and $\mathrm{CO} 2$ concentration. They can control the speed of the fans (Nielsen \& Drivsholm, 2010), modulates individually inputs and outputs air flowrates (Faure, Losfeld, Pollet, Wurtz, \& Ouvrier Bonnaz, 2018) or even all at the same time (Laverge, Van Den Bossche, Heijmans, \& Janssens, 2011). However, most of them are based on mechanical exhaust ventilation. When a supply-only ventilation system, like the Positive Input Ventilation (PIV) presented in section 2.1., is required for the control and the process of the supply air, it could be also very interesting to add more control on the air outlets according to different IAQ measurements in order to further improve the system efficiency.

This paper introduces a new simple combination of a supply-only mechanical ventilation system with innovative active air vents. In order to check the relevancy of such an approach, the first step outlined here is the experimental evaluation of the influence of this combination on the air change rates of different rooms in a house.

\section{Description of the tested system}

\subsection{Positive input ventilation (PIV)}

The Positive Input Ventilation (PIV) is a mechanical ventilation that draws fresh air from the outside, filters and pre-heats or pre-cools it before blowing it through two or more supply points inside the building. Thus, the whole building is slightly pressurized, the air circulates through the door's undercuts and goes out through intentional outlets. As with classical exhaust ventilation system, pollutants are thus removed from wet and polluted rooms to outside. But the fresh air is completely controlled in this case and the system can be easier to set up. The U.S. Department of Energy (U.S. Department of Energy, 2002) introduces supply ventilation systems as relatively simple and inexpensive systems that allow a good control of the incoming air (including pollens and dust filtering) while discouraging the entry of pollutants from outside the living space and avoiding back drafting of combustion gases from fireplaces and appliances. The performance of such a system has been studied and optimized by (Rahmeh, 2014) and by (Ouvrier-Bonnaz, Rahmeh, Stephan, \& Potard, 2015) for instance.

Current PIVs already vary the global blown air flowrate according to the indoor relative humidity (sensor placed in the living-room for instance) and the outdoor absolute humidity (sensor placed at the ventilator output). So far, the foul air is exhausted through passive air vents. Thus the air path inside the building cannot be significantly modulated according to the state of the different rooms. The use of the Active Air Vents described below instead of passive air vents would further improve the PIVs' operation.

\subsection{Active air vents (AAVs)}

Active Air Vents (AAVs) are small motorised dampers, patented by BUBENDORFF (Fritsch, 2018). They are made up of:

- One main opened fixed plastic frame;

- One smaller opened metallic frame on the opening of the main frame, operated by an electric motor;

- One slat between the fixed frame and the mobile frame, independent so that it can close the opening when the mobile frame is opened, thereby preventing the outside air from entering the house this way (such as a double check valve); 

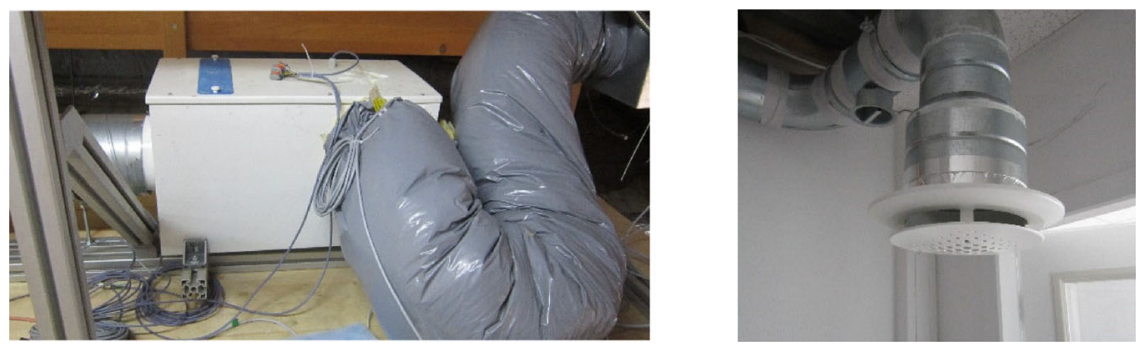

Figure 1. Pictures of the Positive Input Ventilation in the experimental house - Left: Central ventilation device in the attic, Right: Air diffuser in the first floor hall.
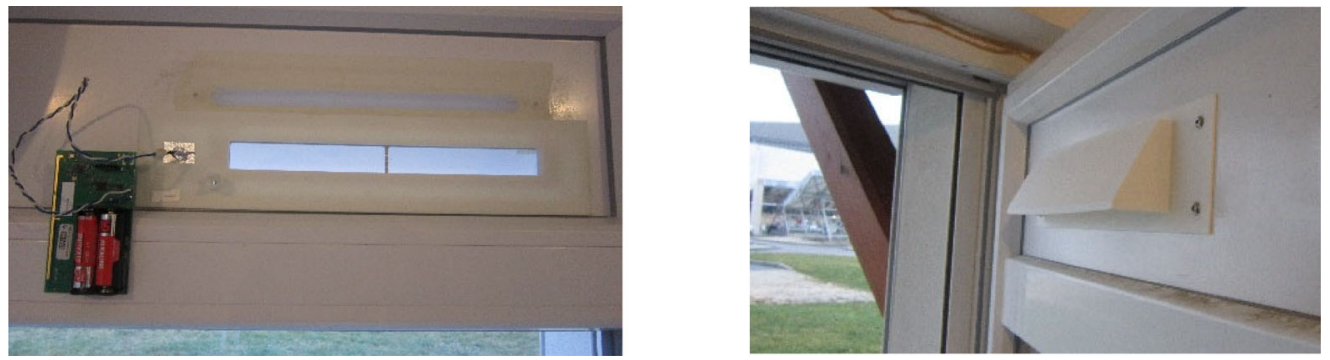

Figure 2. Pictures of one AAV prototype in the experimental house - Left: From inside, Right: From outside.

- One electronic card that controls the motor, measures IAQ variables close to the opening, sends and receives information from the other AAVs.

As introduced in section 1, nowadays, some devices already use pollutants measurements in several rooms to adjust their air extraction. However, most of them are implemented on mechanical exhaust ventilations making it impossible to benefits from the advantages of the supplyonly mechanical ventilation (see section 2.1). AAVs are easy-to-install and easy-to-use modules that would further improve the air quality management of a PIV.

For the tests presented in this paper, AAV prototypes were set up in upper parts of every window of the experimental house (see Figure 2).

Thanks to its different parts, an AAV can have three different positions (see Figure 3, where the mobile frame is marked to clearly identify its position):

a. "Minimal position" - the mobile frame is completely closed on the main frame with an adjusting screw that leaves a slight opening;

b. "Maximal position" - the mobile frame is completely opened and the pressure difference between the inside (high pressure) and the outside (low pressure) of the building maintains the slat on the metallic frame;

c. "Non-return damper" - the mobile frame is completely opened but the higher outdoor pressure closes the slat on the opening so that the outside air cannot enter the house.

The control card measurements and communications enable the closing or opening of a AAV according to its own measurement and to the measurements of the other AAVs, thereby allowing a possible concerted action.

\subsection{Combination of PIV and AAV}

The combination of PIV with AAVs is expected to improve the IAQ of the building by increasing efficiently the air change rate of a room when needed. The fresh air blown by the PIV in the 


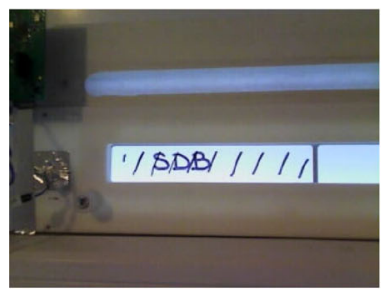

(a)

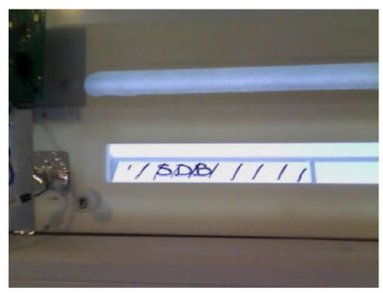

(b)

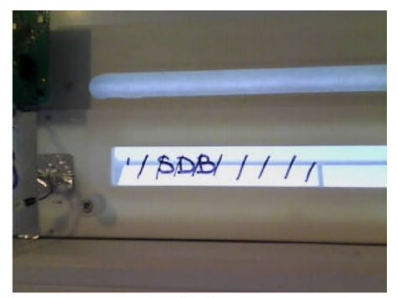

(c)

Figure 3. Pictures of the 3 possible positions of a tested AAV - (a) Minimal position (b) Maximal position (c) Nonreturn damper.

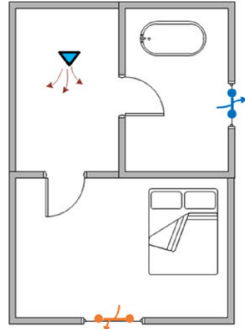

(a)

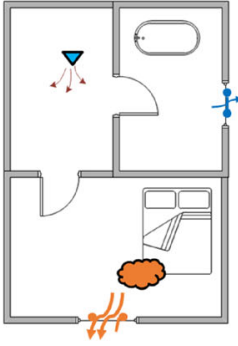

(b)

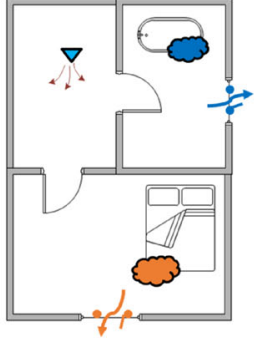

(c)

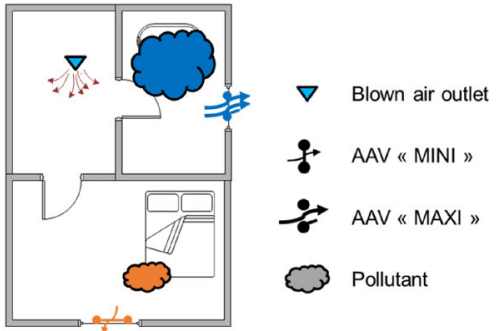

(d)

Figure 4. Different possible states of the combination of PIV and AACs to improve efficiently the IAQ of the building - (a) Steady State (b) Pollutants in one room with autonomous action (c) Pollutants in several rooms with autonomous actions (d) Critical level of pollutants in one room and concerted action.

building can be smartly directed to the most polluted rooms. Hence, with an appropriate IAQ sensor-based controller - not studied in this paper which only focus on the local air change rate potential - this combination would enable the optimization of the pollutants evacuation without necessarily changing the global air change rate of the building.

For instance, the operation steps could be as follow (see Figure 4):

a. Initial state - standby mode: the IAQ is satisfactory in all rooms of the building, every AAV is in "Minimal position" so the fresh air from PIV is distributed in the different rooms in an almost balanced way.

b. Foul air in one room - autonomous action: the concentration of a pollutant is high in one room, the AAV of this room switches to the "Maximal position" so the fresh air from PIV is preferably directed to this room.

c. Foul air in several rooms - autonomous actions: the concentration of a pollutant is high in several rooms but still at a reasonable level, the AAV of those rooms are in "Maximal position" so the air change rate is increased in all those rooms at the same time.

d. Foul air in several rooms - concerted actions: the concentration of a pollutant is high in several rooms and especially in one room where the concentration is above a critical level. The AAV of this room holds the "Maximal position" while all others switch to "Minimal position", so the critical room is treated in priority until its pollutant level returns to an appropriate level. The warning signal can also be sent to the PIV in order to temporarily increase the fresh air flow rate.

\section{Experimental protocol}

\subsection{Goal of the tests and global approach}

The goal of the tests presented in this paper is to quantify the impact of the studied PIV + AAVs combination and the different steps presented in section 2.3 on the air circulation in a building. 

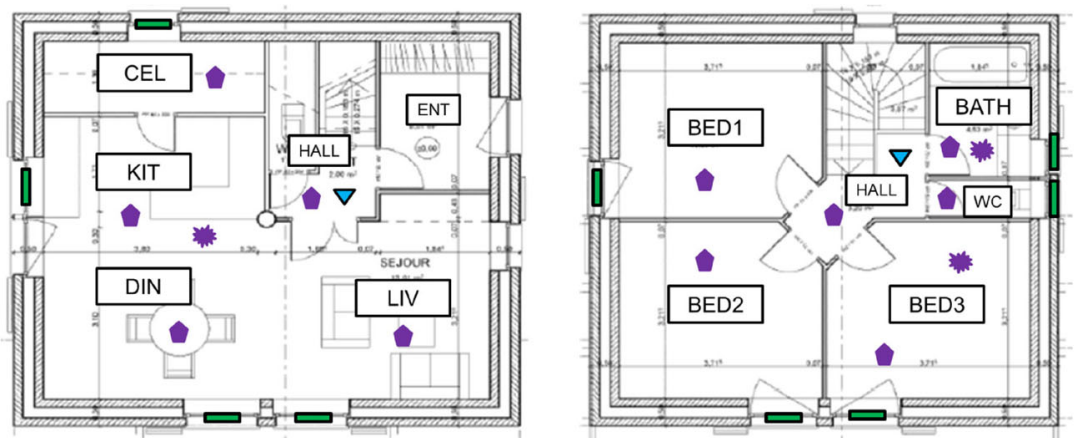

Active Air Vent

Blown air outlet

$\mathrm{CO} 2$ source

CO2 sensor

Figure 5. Introductionof the experimental house - Left: Plan of the first floor. Right: Plan of the second floor.

No specific regulation is considered here (no specific pollutants levels for AACs opening for instance). The main idea is to assess the air change rate of different rooms of the building according to the possible positions of AAVs and fresh air flow rate in a real scale. To do so, a PIV and AAVs are installed in an experimental house. For each test, the required configuration (mainly fresh air flowrate and AAVs position) is setup. The air change rate is estimated thanks to $\mathrm{CO} 2$ used as trace gaz. Each test is repeated several times in order to estimate the variability of the results.

\subsection{Experimental setup}

The equipped experimental house (see Figure 5) is located in Le Bourget du Lac (France). It was built in 2011 with a recent constructive principle. The air tightness of the building was characterized thanks to blower door tests: the air change rate was $0.26 \mathrm{vol} / \mathrm{h}$ at $50 \mathrm{~Pa}\left(69 \mathrm{~m}^{3} / \mathrm{h}\right)$ at the end of the construction work. The living area, represented on Figure 5 is about $100 \mathrm{~m}^{2}$, on two levels:

- First floor: one large room (kitchen [KIT], dining [DIN] and living room [LIV]) and a cellar [CEL];

- Second floor: 3 bedrooms ([BED1], [BED2] and [BED3]), one bathroom [BATH], one toilet $[\mathrm{WC}]$.

The PIV is set up in the attic. The fresh air is blown through two air outlets: one in the hall of each level (see Figures 5 and 1). The global blown air flowrate is measured thanks to an ultrasonic air flow meter (ULTRAFLUX 2000). AAVs are set up in upper parts of every window of the experimental house (see Figures 5 and 2). Thus, AAVs substitute classic air vents in every room, even in the wet rooms (bathroom and kitchen). Sensors (KIMO COT 212) measure the CO2 concentration in the main rooms of the building. A set of $\mathrm{CO} 2$ bottles, pressure reducer and gas pipes enable the injection of pure $\mathrm{CO} 2$ in the required room. A fan is used to homogenise the gas for the initialization of the test (see section 3.4). The complete experimental setup is summarized in Figure 5.

\subsection{Tested configurations}

The tests are carried out in 3 different rooms:

- $\quad$ [BATH]: Bathroom (second floor - volume around $10 \mathrm{~m}^{3}$ );

- [BED3]: One bedroom (second floor - volume around $31 \mathrm{~m}^{3}$ ); 
- $\quad[K I T]$ : Kitchen + Dining + Living room (first floor - volume around $86 \mathrm{~m}^{3}$ ).

For each room, the air change rate is evaluated for different configurations of the combination:

- $\quad$ [REF]: With a classic static air vent (ANJOS VM-G self-regulation units);

- $\quad[M I N]:$ With all the AAVs of the room at the "Minimal position";

- [MAX]: With all the AAVs of the room at the "Maximal position".

For the first case, every window is equipped with a classic air vent (no AAV at all in the building). For all other tests, classic air vents are removed and the AAVs of the other rooms remain at the "Minimal position", except for some of the "concerted operation" tests in which both bathroom's and bedroom's AAV are opened together to estimate the potential of the concerted action (see section 2.3 and 4.2). All internal doors are properly undercut and kept closed during the tests. All blinds are partially closed except for the tested room. The nominal speed of the PIV fan for this house (speed " 2 ") remains the same for all those tests except for some of the "concerted operation" tests: the speed is occasionally raised to estimate the impact of a possible communication (see section 2.3 and 4.2).

\subsection{Air change rate estimation}

The air change rate for each test is estimated thanks to $\mathrm{CO} 2$ used as a trace gas. Considering (Persily, 2016) recommendations, the procedure is as follow:

- The experimental setup is tuned according to the room and the configuration to be tested;

- The studied room is filled with $\mathrm{CO} 2$ up to a high concentration, around 5000ppm, with the homogenisation fan turned on;

- The CO2 injection is stopped and so is the fan a couple of minutes later;

- The decrease of the $\mathrm{CO} 2$ concentration is measured to estimate the air change rate.

As described by (Etheridge \& Sandberg, 1996), the CO2 mass balance inside the studied room, taking into account the incoming and the outgoing $\mathrm{CO} 2$, links the air change rate and the $\mathrm{CO} 2$ concentration variation (see equation (1)).

$$
\tau . d t=\frac{d C}{C_{e}-C}
$$

According to equation (1), the air change rate $(\tau)$ can be estimated by computing the negative slope of the time evolution of the logarithm of the difference between the concentration in the studied room $(C)$ and in its environment $\left(C_{e}\right)$. In this case, the concentration $C_{e}$ is considered as the measured concentration in the halls, where the PIV blows the fresh air (first floor hall for the tests in the kitchen, second floor hall for the tests in the bathroom and the bedroom). The inherent hypothesis is that the fresh air always goes from the halls to the studied room and is then evacuated outside. The opposite case has never been observed on those tests. An example of the air change rate estimation is presented on Figure 6. For all the results selected for this analysis, the regression coefficient of the air change rate estimation is above 0.98 . The equivalent room exhaust air flowrate is also estimated multiplying the air change rate by the volume of the room (see section 3.3). 


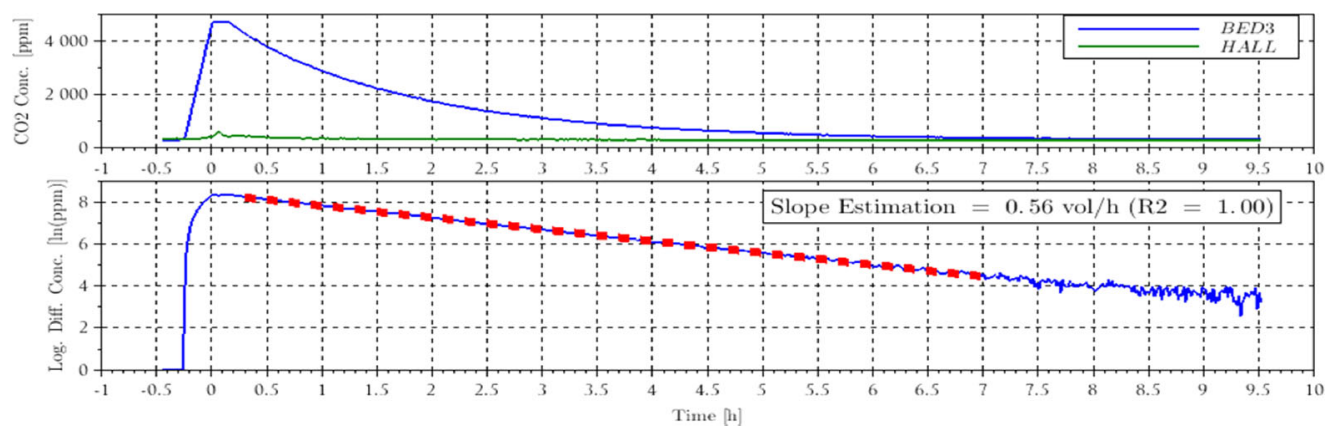

Figure 6. Estimation of the air change rate for one test - Upper: $\mathrm{CO} 2$ concentrations in the studied room and its environment. Lower: Logarithm of the differential concentration and slope estimation (red dots).

Table 1. Results of the tests for characterizing the AAVs' autonomous operation.

\begin{tabular}{|c|c|c|c|c|c|c|}
\hline Room & $\begin{array}{c}\text { AAV } \\
\text { Configuration }\end{array}$ & PIV fan speed & Number of tests & $\begin{array}{c}\text { Global blown } \\
\text { air flowrate } \\
\text { [m3/h] }\end{array}$ & $\begin{array}{c}\text { Air change rate } \\
{[\mathrm{vol} / \mathrm{h}]}\end{array}$ & $\begin{array}{c}\text { Room exhaust } \\
\text { air flow rate } \\
{[\mathrm{m} 3 / \mathrm{h}]}\end{array}$ \\
\hline$\overline{B E D}$ & REF & 2 & 3 & $148(\sigma=1)$ & $0.58(\sigma=0.02)$ & $18(\sigma=1)$ \\
\hline BED & MIN & 2 & 7 & $159(\sigma=2)$ & $0.66(\sigma=0.05)$ & $21(\sigma=1)$ \\
\hline BED & MAX & 2 & 4 & $160(\sigma=1)$ & $1.53(\sigma=0.04)$ & $48(\sigma=1)$ \\
\hline BATH & REF & 2 & 3 & $150(\sigma=3)$ & $1.34(\sigma=0.13)$ & $14(\sigma=1)$ \\
\hline BATH & MIN & 2 & 4 & $157(\sigma=6)$ & $1.61(\sigma=0.41)$ & $17(\sigma=4)$ \\
\hline BATH & MAX & 2 & 4 & $157(\sigma=6)$ & $3.74(\sigma=0.76)$ & $39(\sigma=8)$ \\
\hline KIT & REF & 2 & 2 & $151(\sigma<0.5)$ & $0.85(\sigma=0.03)$ & $73(\sigma=3)$ \\
\hline KIT & MIN & 2 & 5 & $162(\sigma=5)$ & $1.03(\sigma=0.17)$ & $88(\sigma=14)$ \\
\hline KIT & MAX & 2 & 3 & $167(\sigma=3)$ & $1.51(\sigma=0.13)$ & $130(\sigma=11)$ \\
\hline
\end{tabular}

\section{Results}

Results from 52 tests are used to characterize the air change rate in the different rooms, for the different configurations. Each configuration is tested several times in order to take into account the possible variability of the results due to the operating conditions, mainly the weather conditions during the tests. For each characteristic presented below (air change rate and global blown air flow rate), the number of tests considered and the standard deviation $\sigma$ is presented (in brackets).

\subsection{Autonomous operation of the AAVs in each room}

Results of the tests for characterizing the AAVs' autonomous operation are presented in Table 1 and Figure 7. The autonomous operation in one single room is described by steps a) and b) in section 2.3 and Figure 4. The tests were carried out between January and June 2018.

The global blown air flow rate varies from 148 to $169 \mathrm{~m}^{3} / \mathrm{h}$ whereas the fan speed remains the same for each test. This is due to the changing weather conditions that can naturally introduce variation on the volumetric flow rate of a fan even with the same speed. That is why Figure 7 shows air change rate estimations according to the measured global air flow rate. This representation allows to clearly distinguish the impact of the supplied air flow from the impact of the AAV configuration on the air change rate of each room.

Firstly, for each room, considering the global blown air flowrate changes and the standard deviations, the air change rate with the minimal position of the AAV is similar to the case with classic air vents. The gap could be even reduced by working further on the setup and the tuning of the AAVs in their "minimal position". Secondly, comparing the results between "minimal position" and "maximal position", still including their standard deviation, it can be 

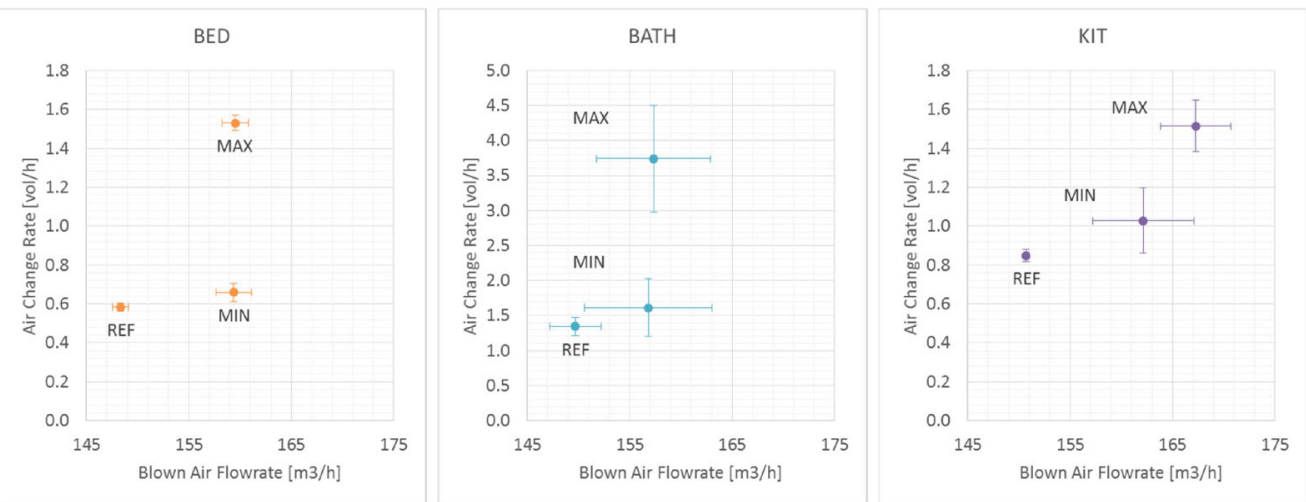

Figure 7. Evolution of the air change rate according to the AAV configuration in each tested room.

stated that the opening of the active air vent raises significantly the air change rate for each room: from 1.5 times more in the kitchen to 2.3 times more in the bathroom when considering the average values. This means that in this case, an appropriate control of the autonomous action of the AAVs would treat basic IAQ issues very efficiently by changing significantly the air change rate of a room when needed, without necessarily changing the blown air flowrate.

\subsection{Concerted operations between AAVs and the PIV}

Additional tests were carried out in order to evaluate the relevance of a concerted action between the AAVs and with the PIV as well. The concerted operations in one single room is described from step a) to d) in section 2.3 and Figure 4. For those tests, the trace gas is injected simultaneously in both the bedroom and the bathroom. The $\mathrm{CO} 2$ injection is then stopped at the same time for both rooms and the air change rate is estimated over the same period of $\mathrm{CO} 2$ concentrations decrease. The tests were carried out between July and August 2018. For this campaign, some AAV prototypes were changed and the bathroom and bedroom blinds were both kept opened. So the following results cannot be strictly compared with the previous ones in section 4.1. Results are introduced in Figure 8 and Table 2 hereunder.

The impact of the AAVs and PIV operations is clearly visible:

- From step a) to b) (pollution in the bedroom for example):

The opening of the AAV in the bedroom increases significantly the air change rate in the bedroom. Probably due to the global air pressure loss configuration given by all the AAVs in the building, this hardly impacts the air change rate in the bathroom.

- From step b) to c) (additional pollution in the bathroom for example):

The opening of the AAV in the bathroom highly increases the air change rate in the bathroom but hardly impacts the air change rate in the bedroom. The latter is a little increased in average but not significantly with regards to the standard deviations. A larger amount of the global fresh air from the PIV flows through both rooms in this c) case.

- From step c) to d) (critical pollution level in the bathroom for example): 


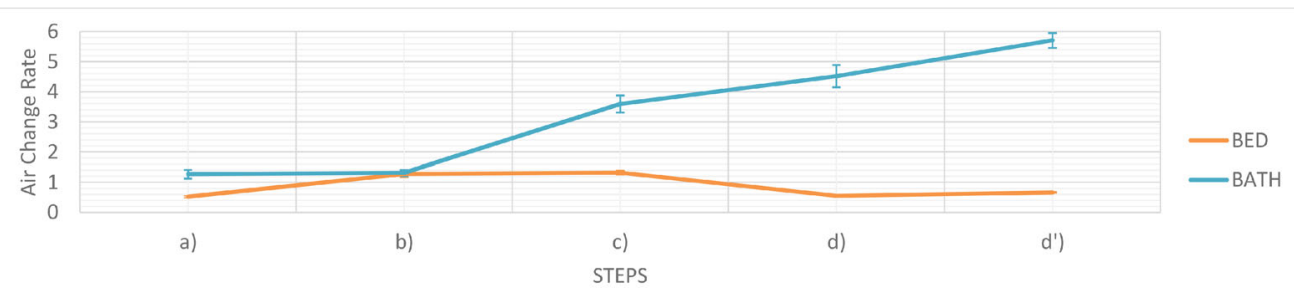

Figure 8. Evolution of the air change rate in the bedroom and the bathroom according to the possible steps of the AAVs and PIV concerted operation.

Table 2. Results of the tests for characterizing the AAVs' concerted operation.

\begin{tabular}{|c|c|c|c|c|c|c|c|c|c|}
\hline Step & $\begin{array}{c}\text { AAV } \\
\text { config. in } \\
\text { the } \\
\text { bedroom }\end{array}$ & $\begin{array}{c}\text { AAV } \\
\text { config. in } \\
\text { the } \\
\text { bathroom }\end{array}$ & $\begin{array}{c}\text { PIV } \\
\text { fan speed }\end{array}$ & $\begin{array}{l}\mathrm{Nb} \text { of } \\
\text { tests }\end{array}$ & $\begin{array}{c}\text { Global } \\
\text { blown air } \\
\text { flowrate } \\
\text { [m3/h] }\end{array}$ & $\begin{array}{c}\text { Air change } \\
\text { rate in the } \\
\text { bedroom } \\
{[\mathrm{vol} / \mathrm{h}]}\end{array}$ & $\begin{array}{c}\text { Air change } \\
\text { rate in the } \\
\text { bathroom } \\
{[\mathrm{vol} / \mathrm{h}]}\end{array}$ & $\begin{array}{c}\text { Bedroom } \\
\text { exhaust air } \\
\text { flow rate } \\
{[\mathrm{m} 3 / \mathrm{h}]}\end{array}$ & $\begin{array}{c}\text { Bathroom } \\
\text { exhaust air } \\
\text { flow rate } \\
{[\mathrm{m} 3 / \mathrm{h}]}\end{array}$ \\
\hline a) & MIN & MIN & 2 & 4 & $168(\sigma=2)$ & $0.52(\sigma=0.03)$ & $1.27(\sigma=0.14)$ & $16(\sigma=1)$ & $13(\sigma=2)$ \\
\hline b) & MAX & MIN & 2 & 3 & $171(\sigma=1)$ & $1.28(\sigma=0.12)$ & $1.31(\sigma=0.10)$ & $40(\sigma=4)$ & $14(\sigma=1)$ \\
\hline c) & MAX & MAX & 2 & 3 & $168(\sigma=3)$ & $1.32(\sigma=0.07)$ & $3.59(\sigma=0.28)$ & $41(\sigma=2)$ & $37(\sigma=3)$ \\
\hline d) & MIN & MAX & 2 & 3 & $165(\sigma=4)$ & $0.56(\sigma=0.02)$ & $4.52(\sigma=0.37)$ & $17(\sigma=1)$ & $47(\sigma=4)$ \\
\hline$\left.d^{\prime}\right)$ & MIN & MAX & 4 & 4 & $236(\sigma=18)$ & $0.66(\sigma=0.02)$ & $5.71(\sigma=0.25)$ & $21(\sigma=1)$ & $59(\sigma=3)$ \\
\hline
\end{tabular}

The closing of the AAV in the bedroom brings a significant extra increase of the air change rate - around $25 \%$ in average in this case. The air change rate level in the bedroom is similar as the step a) case. The air flow rate estimated in both rooms is greater than the b) step while the global blown air flowrate is similar. It seems that the opened bathroom AAV has a greater capacity to collect the fresh blown air. This is probably due to global air pressure loss configuration in the building.

- $\quad$ From step d) to d') (PIV fan speed increased by 2 levels):

When the PIV fan speed is increased, the air change rate raises by another $25 \%$ in the bathroom in this case.

Those results show that the communication between AAVs and the PIV could treat very efficiently critical pollution cases - when the bathroom is too humid for instance. In the latter configuration, the bathroom air would be completely renewed in a few dozen minutes.

\section{Conclusions}

A combination of a central Positive Input Ventilation (PIV) and distributed Active Air Vents (AAVs) as an alternative to classical air vents in every room, was tested in an experimental house. Several tests were carried out to characterize the air change rate of different rooms with different combinations of AAVs and PIV. The results can be summarized as follows:

- The air change rate of minimal position AAVs is similar to classic ones,

- The opening of the AAV in a room raises significantly its air change rate when all others are in "MINI" position (from 1.5 times more in the kitchen to 2.3 times more in the bathroom),

- The closing of the bedroom air vent when the bathroom air vent is opened raises by around $25 \%$ the air change rate of the bathroom. This could be very helpful as a concerted action to treat critical situations, when the bathroom is exceedingly humid for instance. 
Those results are promising since the air change rate of the tested rooms can be significantly modulated when needed. Further numerical studies would be required to generalize those observations:

- The experimental house is a tight dwelling. Even if AAVs and classic air vents are compared in the same operation conditions, the sensitivity of the system to the envelope leakage must be evaluated.

- The AAVs opening has not the same influence according to the room and the position of fresh air supply points. The influence of the air pressure loss repartition in the house must be evaluated too.

The use of AAVs with a PIV would then offer a lot of possibilities to improve the IAQ of a house. Contaminants to be processed must be selected and the different threshold must be set. The hysteresis opening of the active air vent - as autonomous operation - would have a significant impact on the pollutants' evacuation of a room. This could be even enhanced thanks to a concerted action with appropriate critical thresholds. The tested system could thus smartly modulate the air change rate of each room (damp room as well as living room) according to its pollution level.

\section{Disclosure statement}

No potential conflict of interest was reported by the author(s).

\section{Funding}

This work was supported by the French Unique Interministerial Fund (FUI).

\section{Notes on contributors}

Dr. Antoine Leconte received his PhD from Université de Grenoble in 2011 after an engineer diploma in 2008 from Grenoble INP. He has been working in the development of test methods for Solar Combisystems and has a strong experience in thermal system simulation and testing. He joined the INES Team in the "Building and Thermal System Laboratory" as research engineer and project manager. He is now involved in several fields of HVAC systems including ventilation.

Clément Lafféter has a Master's degree from Lorraine INP - ENSEM (Higher National School of Electricity and Mechanics). He works for VENTILAIRSEC since 2015, as Innovation Manager since 2018. He works with institutional boards, a wide variety of other industrial companies and research laboratories to make solutions that address the challenge of the indoor air quality, energy performance and thermal comfort in buildings. Clément has experience in thermal exchanges and thermodynamic, indoor and outdoor air quality, and fluid mechanics. He is in charge for VENTILAIRSEC to set and follow several experimental projects, testing different strategies to combine demand-controlled mechanical supply ventilation systems with several heat generators such as heat pumps or solar technology. Clément spent his Master Thesis working on the new energy and aeraulic computation engine at the Scientific and Technical Center for Building (CSTB).

Thomas Fritsch has an engineer diploma in 1994 from Ecole Centrale Lille. He has been working for 17 years as project leader and development leader in heating control systems, hot water tanks, heat pumps and thermal solar panels. He joined the Bubendorff team 9 years ago as head of the motor development team. He is also involved in the master2 energy and sustainable development management at the Unistra university of Strasbourg.

Nicolas Giordano Mechanical engineer from the ENI in Metz since 1998, Mr. Nicolas GIORDANO has significant experience as a $R \& D$ engineer in metal structure. After trying his hand at entrepreneurial adventure, he joined BUBENDORFF in 2017 as electromechanical development manager for the roller shutters motors.

Julien Escaich received a Master's degree in Electrical Engineering from ESIEE in 2007. He has been working as an R\&D director, coordinating the development of HVAC solutions for housing at affordable prices for the last 5 years. 
He has also experience in Renewable Energy since he was previously in charge of the European technical development of a Thermal Canadian Solar technology named SolarWall. He is now developing an activity to support individuals in the process of Sustainable Building Energy Efficiency Retrofit (BEER).

Ophélie Ouvrier-Bonnaz Graduated her Master Diploma in thermal engineering from Joseph Fourier University of Grenoble in 2006 with a specialization in fluid mechanics Modeling. She had been working for 6 years at FAURE $\mathrm{QEI}$, engineering specialized in cleanroom, as HVAC engineer for a wide range of industries. She joined CEA as a research engineer at INES in 2012, specialized in Ventilation, Building Energy and aeraulic simulation. She has been head of integration energetic systems laboratory since 2016.

\section{References}

Chenari, B., Dias Carrilho, J., \& Gameiro Da Silva, M. (2016). Towards sustainable, energy-efficient and healthy ventilation strategies in buildings: A review. Renewable and Sustainable Energy Reviews, 59, 1426-1447. https://doi. org/10.1016/j.rser.2016.01.074

Direction générale de la Santé. (2013). Plan d'actions sur la Qualité de I'Air Intérieur. Obtido de https://solidaritessante.gouv.fr. https://solidarites-sante.gouv.fr/IMG/pdf/Plan_Qualite_de_I_air_interieur_octobre_2013.pdf

Etheridge, D., \& Sandberg, M. (1996). Building ventilation: Theory and measurment. John Wiley \& Sons.

European Commission. (2013). Environment: New policy package to clean up Europe's air. Obtido de http://europa. eu/: http://europa.eu/rapid/press-release_IP-13-1274_en.pdf

Faure, X., Losfeld, F., Pollet, I., Wurtz, E., \& Ouvrier Bonnaz, O. (2018). Resilient Demand Control Ventilation system for dwellings [Paper presentation]. 39th AIVC Conference, Juna Les Pins, France.

Fisk, W. J., \& De Almeida, A. T. (1998). Sensor-based demand-controlled ventilation: A review. Energy and Buildings, 29(1), 35-45. https://doi.org/10.1016/S0378-7788(98)00029-2

Fritsch, T. (2018). Europe Patente $N^{\circ}$ EP3396267 A1.

Guyot, G., Sherman, M. H., \& Walker, I. S. (2018). Smart ventilation energy and indoor air quality performance in residential buildings: A review. Energy and Buildings, 165, 416-430. https://doi.org/10.1016/j.enbuild.2017.12.051

Laverge, J., Van Den Bossche, N., Heijmans, N., \& Janssens, A. (2011). Energy saving potential and repercussions on indoor air quality of demand controlled residential ventilation strategies. Building and Environment, 46(7), 1497-1503. https://doi.org/10.1016/j.buildenv.2011.01.023

Liddament, M. W. (2000). A review of ventilation and the quality of ventilation air. Indoor Air, 10, $193-199$.

Nielsen, T. R., \& Drivsholm, C. (2010). Energy efficient demand controlled ventilation in single family houses. Energy and Buildings, 42(11), 1995-1998. https://doi.org/10.1016/j.enbuild.2010.06.006

Ouvrier-Bonnaz, O., Rahmeh, M., Stephan, L., \& Potard, M. (2015). Whole-house air distribution with a supply-only ventilation system VMI ${ }^{\circledR}$ for an optimum air change. In CLIMAMED 2015 Congress Sustainable Energy Performance of Buildings.

Persily, A. K. (2016). Field measurement of ventilation rates. Indoor Air, 26(1), 97-111. https://doi.org/10.1111/ina. 12193

Rahmeh, M. (2014). Etude expérimentale et numérique des performances de la ventilation mécanique par insufflation: qualité de l'air intérieur dans les bâtiments résidentiels. Université de la Rochelle.

U.S. Department of Energy. (2002). Whole House Ventilation Systems - Improved control of air quality - Technology Fact Sheet. Obtido de. https://www.nrel.gov: https://www.nrel.gov/docs/fy03osti/26458.pdf 